\title{
Results of the femur fractures treated with the new selfdynamisable internal fixator (SIF)
}

\author{
Milorad Mitkovic $\cdot$ S. Milenkovic $\cdot$ I. Micic $\cdot$ \\ D. Mladenovic $\cdot$ Milan Mitkovic
}

Received: 12 January 2011/ Accepted: 25 September 2011/Published online: 28 October 2011

(C) The Author(s) 2011. This article is published with open access at Springerlink.com

\begin{abstract}
Purpose As axial dynamisation is a recognised method, many authors using interlocking femoral nail perform an additional small operation two months after the primary operation in order to remove one screw so as to provide axial dynamisation. According to the literature, dynamisation happens in about $15-25 \%$ of cases, but it cannot be predicted which patient or fracture will need dynamisation. The aim of this study is to present a new selfdynamisable implant and a minimally invasive method for the internal fixation of different femoral fractures.

Materials and methods The study was conducted between 2000 and 2008 and included 849 patients with 871 fractures receiving the selfdynamisable internal fixator (SIF) for proximal, diaphyseal and distal femur fractures. Results The average operative time was 44 min (23-119 $\mathrm{min})$ and the average fluoroscopy time was $12 \mathrm{~s}(6-92 \mathrm{~s})$, while the average blood loss was $90 \mathrm{ml}(60-250 \mathrm{ml})$ when a minimally invasive technique was used. None of the patients developed complications during the intra-operative period. Complete follow-up was available in 726 patients with 738 fractures. The healing time was 3.9 months (3-9 months). Healing was achieved in $99.1 \%$ of patients. Superficial infection developed in seven fixations $(0.9 \%)$, while deep infection developed in four patients $(0.5 \%)$.
\end{abstract}

Electronic supplementary material The online version of this article (doi:10.1007/s00068-011-0157-7) contains supplementary material, which is available to authorized users.

M. Mitkovic $(\varangle) \cdot$ S. Milenkovic · I. Micic · D. Mladenovic · M. Mitkovic

Medical faculty, Clinical Center, Orthopaedic and Traumatology

Clinic, University of Nis, Bul. Dr. Z. Djindjica 48,

18000 Nis, Serbia

e-mail: mitkovic@gmail.com
Screw-breaking occurred within 6-18 weeks in 19 fixations (2.6\%). Cut-out phenomenon happened in 24 cases. Spontaneous axial dynamisation was observed in 71 (23.8\%) out of 738 fractures, being $5 \mathrm{~mm}$ on average (2-12 mm).

Conclusion The SIF is an effective method for the treatment of femoral fractures. This method is particularly valuable in the treatment of comminuted fractures with regard to minimally invasive surgery.

Keywords Femur - Fracture - Selfdynamisable internal fixator (SIF) · Dynamisation · Minimally invasive surgery

\section{Introduction}

Femoral fractures are a common problem in orthopaedic trauma. There are more and more complex femoral fractures involving proximal or distal end and diaphysis. Nail, plate and external fixators have been the most frequently used implants for decades, and they are still present today [1]. Using ordinary plate leads to bone loss, periosteal vascular disturbance [2] and dead space under the plate [3], which can provide conditions for possible infection. However, using current concepts of intramedullary nailing yields high union rates [4]. The external fixator using the extra focal concept does not interfere with vascular damage in the fracture area, especially if closed fracture reduction is achieved. When balanced three-dimensional stability external fixation frames are used, excellent biomechanical conditions are provided [5-8]. Fracture healing is undisturbed and the possibility of dynamisation can further improve callus formation. But the external fixator has disadvantages such as pin tract infection, pin loosening, knee stiffening and patient discomfort. The goal of this 
study is to show a new internal fixator [9] which seems to provide a good alternative treatment for femoral fractures, especially complex fractures as comminuted and segmental, including upper and lower end involvement.

\section{Materials and methods}

\section{Patients}

The study was conducted between 1st January 2000 and 31st December 2008, at the Orthopaedic and Traumatology Clinic of the University of Nis, Serbia. The study used the selfdynamisable internal fixator (SIF) in 849 patients with 871 fractures. Inclusive criteria consisted of fresh closed and type I open fractures of the proximal, diaphyseal and distal femur. Exclusive criteria consisted of pathological fractures, periprosthetic fractures and infection.

There were 524 males and 347 females, with a median age of 52 years (range 15-88 years). The distribution of fractures according to the segment of the femur involved was as follows: proximal femur 651, diaphyseal femur 129 and distal femur 91. In 428 patients, fractures involved the right femur, in 421 the left femur was affected, whereas both sides were involved in 22 patients. Eight hundred and sixty-five fractures were closed and six fractures were classified as type I open fractures according to the Gustilo classification [10]. Regarding open fractures, five were related to diaphyseal and one to supracondylar fractures. The mechanism of injury consisted of motor vehicle accidents in 116 cases, pedestrian accidents in 25 cases, falls in 672 cases, motorcycle accidents in 19 cases and bicycle in 17 cases. According to the AO fracture classification [11], all fractures have been classified as follows: 31-A1 in 51 patients $(6.0 \%), 31-\mathrm{A} 2$ in 276 patients $(31.7 \%), 31-\mathrm{A} 3$ in 324 patients $(37.2 \%), 32-\mathrm{A}$ in 29 patients $(3.3 \%), 32-\mathrm{B}$ in 63 patients $(7.2 \%), 32-\mathrm{C}$ in 37 patients $(4.2 \%), 33-\mathrm{A}$ in 43 patients $(4.9 \%), 33-\mathrm{B}$ in 6 patients $(0.7 \%)$ and $33-\mathrm{C}$ in 42 patients $(4.8 \%)$. Sixty-two patients $(7.3 \%)$ had multiple injuries (head, thorax trauma, abdominal injury, ipsilateral tibial fracture and other). On admission, 164 patients $(19.3 \%)$ were placed on skeletal traction. The average time from injury to operation was 3.4 days (ranging from 1 to 47 days). All patients received pre- and post-operative antibiotics for 2-7 days and low molecular heparin. The follow-up period was 2-4 years. One hundred and twelve patients with fixation of the proximal femur and 11 patients with distal femur fixation left the study, so the remaining number of patients was 726 with 738 fractures. The reasons why $123(14.5 \%)$ patients were lost to follow-up are not known in all cases, but the majority of the population in this region are old-age agriculturers and did not answer to our invitation letter to come for follow-up. Some of the patients originated from far away regions and did not come after a 3-month period for follow-up. So, the analysis of our data from the hospitalisation time relates to all of the 849 patients, while the analysis of data after hospitalisation relates to 726 patients. Hip function was evaluated using the Salvati and Wilson assessment score [12].

The patients were examined at yearly intervals. Gait assessment and evaluation of any tenderness at the fracture site or any pain on weight-bearing were recorded. Hip and knee range of motion were also recorded. Clinical union was defined as the absence of local tenderness at the fracture site and the absence of pain during full weightbearing.

Radiographic evaluation comprised anteroposterior and lateral non-weight-bearing radiographs. The radiographs were analysed for fragment alignment and callus distribution around the fracture site. Radiological union was defined as consolidation of the fracture with the re-establishment of three-cortex continuity, filled with mass of callus, including periosteal callus formation. Radiographs were routinely made and were not standardised.

\section{Implant characteristics}

The main three characteristics of the selfdynamisable internal fixator (SIF) developed by Mitkovic, are: possibility of spontaneous axial dynamisation, preservation of both periosteal and medullary bone blood circulation, and less invasive technique of application. This implant was approved by the National Drug and Medical Devices Agency. The SIF has three basic variants for application on the femur (Figs. 1 and 2). The first variant is for the treatment of fractures involving the upper femur (Figs. 1a and 2a). This variant consists of a trochanteric unit (for dynamic hip screws), which extends distally as a bar. One or two clamps can be fixed to the bar. On the distal end, it has an anti-rotation dynamic unit. On the trochanteric unit, there are three holes, but it is enough to introduce two screws only into the neck and head of the femur. The second variant is for the treatment of diaphyseal fractures. It consists of a specially designed bar and clamps (Figs. 1b and $2 \mathrm{~b}$ ). On one end, there is a hole for an anti-rotation screw and on the opposite end, it has a dynamic antirotation unit (Fig. 3c). The third variant is for the treatment of fractures involving the distal femur. This variant consists of a locking condylar plate, for $95^{\circ}$ condylar screws, and extends proximally as a bar with clamps (Figs. 1c and 2c). On the proximal end, it has an anti-rotation dynamic unit. Each variant is available in three lengths of the bar. The trochanteric variant with a short bar is suitable for the dynamic fixation of pertrochanteric fractures. An antirotation dynamic unit (Fig. 3c) provides the telescoping effect, i.e. biocompression. After application, there is no 

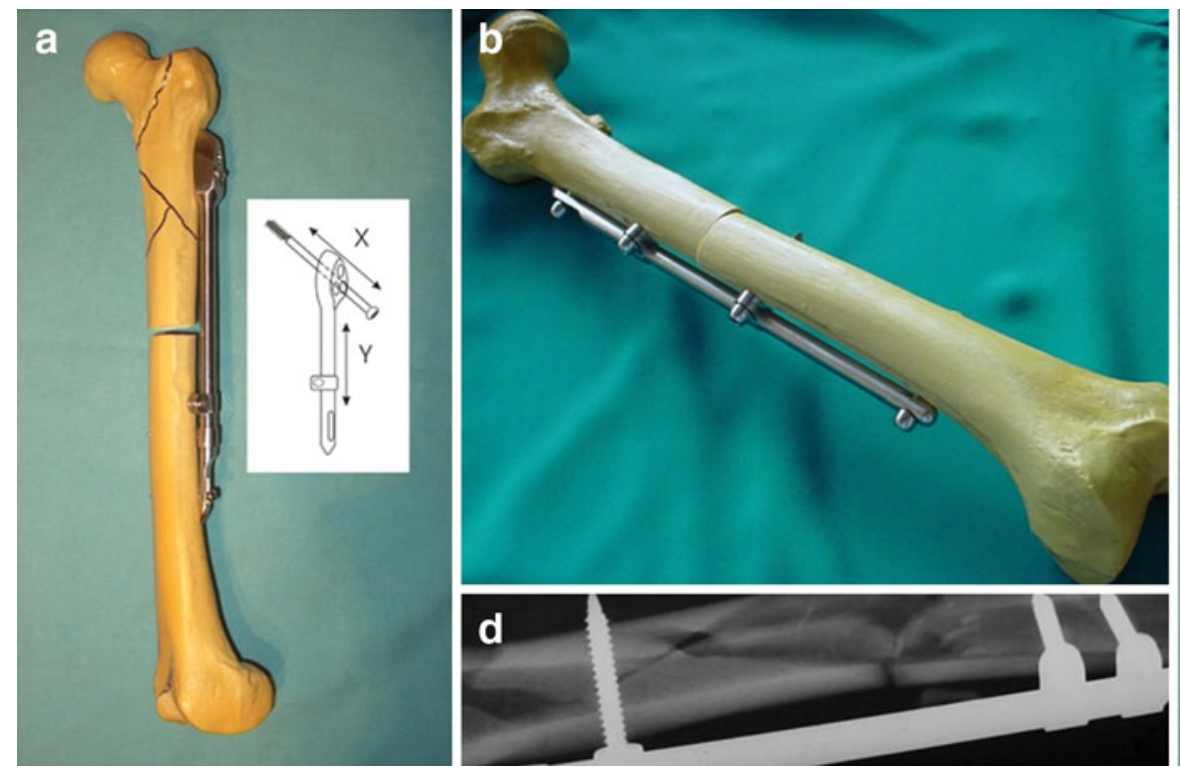

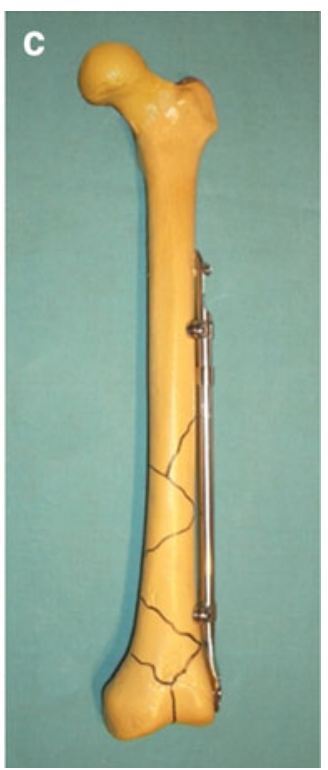

Fig. 1 Three variants of the selfdynamisable internal fixator (SIF). a Trochanteric unit with bar. Insert possibility of dynamisation in both of the two axes: in the femoral neck axis $(x)$ and in the long
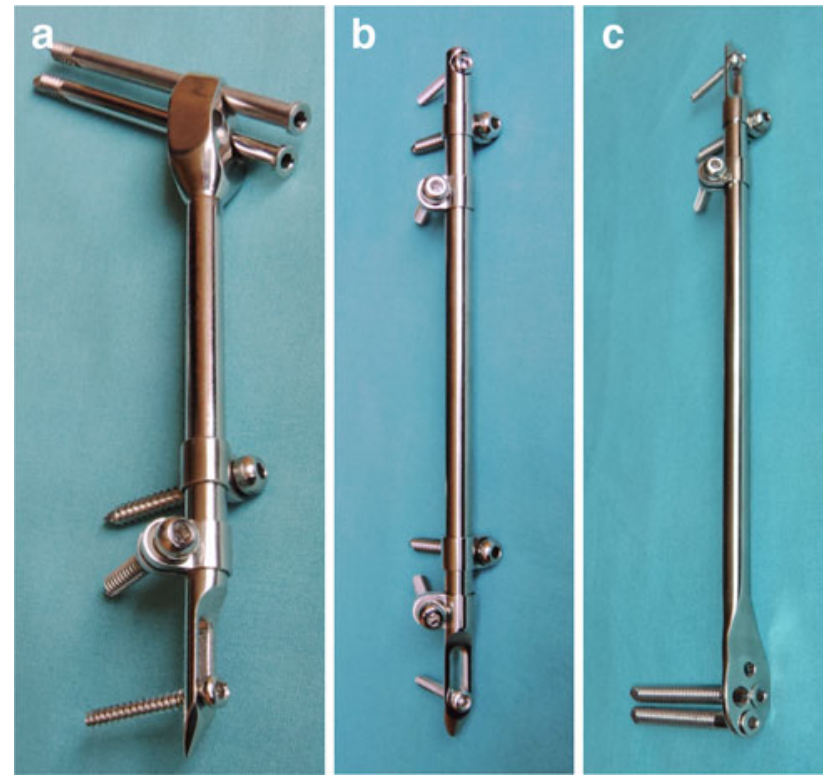

Fig. 2 Photographs of the implant. a Bar with anti-rotating screw in the dynamic unit on one end, with two clamps with corresponding locking screws and the trochanteric unit on the opposite end with two dynamic hip screws inside. b Bar with four clamps, one fixing antirotating screw in a simple hole on one end and with another antirotating screw in the dynamic unit on the opposite end. c Bar with anti-rotating screw in the dynamic unit on one end, with two clamps with corresponding locking screws and with a condylar plate on the opposite end with two locking condylar screws

direct contact between the bar and the bone surface (Fig. 1b, d). The construction of the clamps and screws provides two functions. The first is the possibility of three-dimensional femoral axis (y). b Bar variant. c Condylar plate with locking screws and bar. $\mathbf{d}$ There is no direct contact between the bar and the bone in the fracture area

fixation of each main bone fragment, as each clamp can rotate around the bar, and screws can be applied in a convergent configuration (from the anterior or posterior sides in relation to the bar), thus, providing more biological threedimensional biomechanical conditions (Figs. 2 and 3c). The second function is that the construction of each clampscrew complex provides a little loosening of the clamp in relation to the bar, if there is no fracture healing, so that the bar can glide through the clamp, thus, realising axial telescoping and biocompression on the fracture area. During this telescoping, the rotation of the bar in relation to the clamps is prevented by a dynamic unit on the tip of the bar, since the dynamic unit is supplied with a corresponding antirotation screw (Figs. 2 and 3). If there is no axial contact between fragments on the fracture area, then because of muscle activities and bone fragments micromotion, screws and clamps become loose, leading to spontaneous telescoping. It happens approximately $6-8$ weeks after the fixation. If there is no gap in the fracture area (if there is contact between fragments), then there is no loosening of screws and clamps, because the forces are transmitted mainly through the bone and less through the screws-clamps complexes. Because of this feature, the implant can be regarded as an "Intelligent Implant". It also provides a possibility to make compression on the fracture site intraoperatively. The trochanteric variant has a possibility of dynamisation in two axes (Fig. 1a, insert): in the axis of the femoral neck $x$ and in the long axis of the femur $y$. The SIF (Traffix Ltd., Nis, Serbia) was made of stainless steel (ASTM F 138-2). 
a
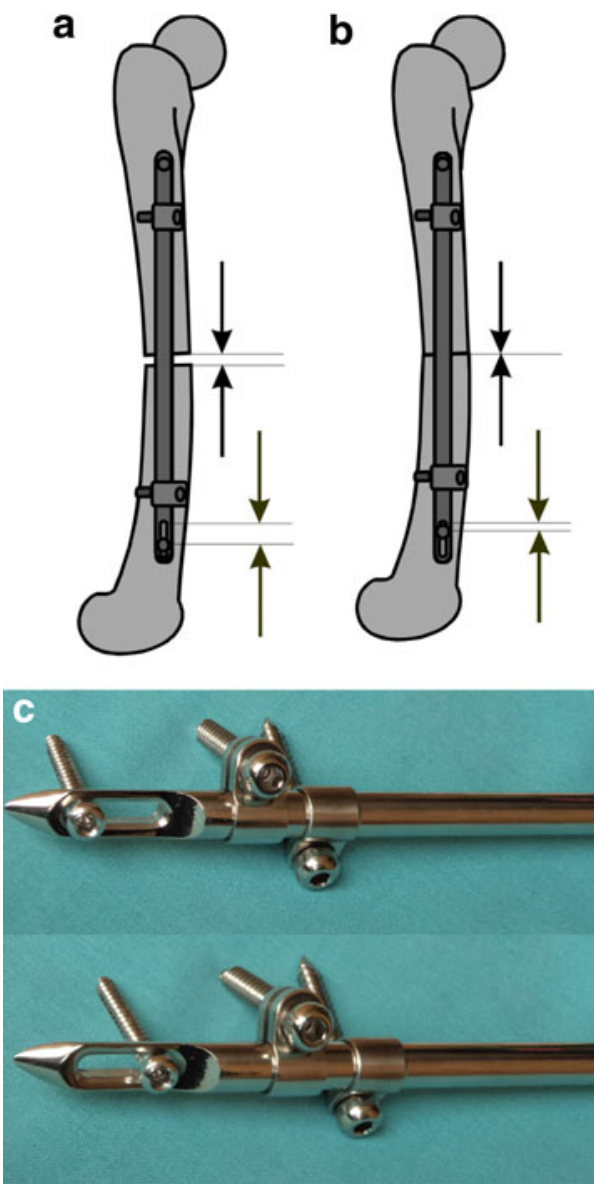

Fig. 3 Scheme of the SIF from the lateral view. a There is a gap on the fracture site; the dynamic unit not activated. b After spontaneous loosening of the distal clamp(s), a telescoping effect starts, the dynamic unit is activated, the distal bone fragment slides proximally and the fracture gap is closed (shown by the arrows in the fracture area). The distal arrows show shortening of the distance between the head of the anti-rotating screw and the proximal end of the slot of the dynamic unit. c Photograph of the dynamic unit before and after dynamisation

This device has been investigated biomechanically in the independent biomechanical laboratory of the Mechanical Faculty, University of Nis, Serbia. It has also been investigated experimentally on a series of 60 animals at the Faculty of Medicine, University of Novi Sad and at the Faculty of Medicine, University of Nis [41].

\section{Operative technique}

The patients with fractures were positioned supine on a radiolucent fracture table. For fracture reduction, a traction table was used. The indirect reduction technique, described below, emphasises soft tissue sparing of the involved fragments and the use of implants in obtaining reduction. In the case of pertrochanteric fractures, the short SIF with a trochanteric unit was used. On the lateral side, a 5-6-cmlong skin incision is made, beginning just distally from the trochanteric ridge. After implant insertion, the fracture reduction is checked fluoroscopically in two directions and fixation is performed. In the case of subtrochanteric femoral fracture, a 5-6-cm-long incision is made proximally and also one incision distally. After tunnelisation and implant insertion, the fracture reduction is checked fluoroscopically in two directions and fixation is performed. The application technique for fixation of the fracture of the distal femur is also performed by two incisions. The difference is that the tip of the implant is introduced in the opposite direction, from distal to proximal, through a 4-5$\mathrm{cm}$-long incision on the lateral condyle level (Fig. 4). The technique of SIF application for the fixation of diaphyseal fractures also uses two 4-5-cm-long incisions.

Post-operatively, the patients were allowed to walk during the first 3 weeks, bearing limited weight which did not exceed the weight of the patient's leg. After that time, weight-bearing was progressively increased until full weight-bearing was introduced 8 weeks after the operation. However, caution is imperative in significantly comminuted fractures and distal intra-articular fractures. In simple fractures it is allowed immediate full weight bearing.

\section{Results}

The average operative time was 44 min (ranging from 23 to $119 \mathrm{~min})$, the average fluoroscopy time was $12 \mathrm{~s}(6-92$ s), the average blood loss with a minimally invasive technique was $90 \mathrm{ml}(60-250 \mathrm{ml})$ and $280 \mathrm{ml}(120-1,050$ $\mathrm{ml}$ ) with regular surgical exposure. A minimally invasive technique was used in 376 fracture fixations (31.7\%) after this technique was developed. The average perioperative transfusion requirement was $0.8 \mathrm{U}$ (ranging from 0 to $3 \mathrm{U}$ ) after a regular approach. The mean hospitalisation period was 7 days (2-26 days).

In the follow-up data, the healing time varied in different parts of the femur. None of the patients developed complications during the intra-operative period. All 129 diaphyseal fractures healed within 4.2 months (3.5-9 months). All mixed fractures affecting diaphysis and proximal femur (7) and including diaphyseal and condylar involvement (11) were placed in the group of diaphyseal fractures. The healing time for trochanteric fractures was 3.5 months (3-5.5 months) and for fracture healing of the distal femur was 3.4 months (3-6.3 months). Union was not achieved in five fixations $(0.9 \%)$ of proximal femur fractures. In four patients, the problem was resolved using hip endoprosthesis and one patient could not be surgically treated because of poor health conditions. Union was not achieved in two fixations $(2.5 \%)$ of distal femur fractures. Superficial infection developed in seven fixations $(0.9 \%)$, while deep infection developed in four patients $(0.5 \%)$. 
a

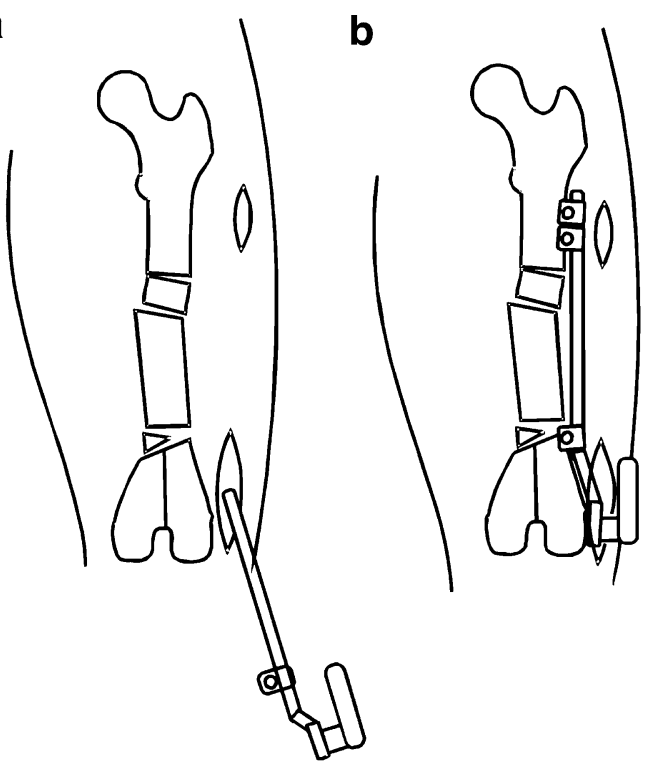

C

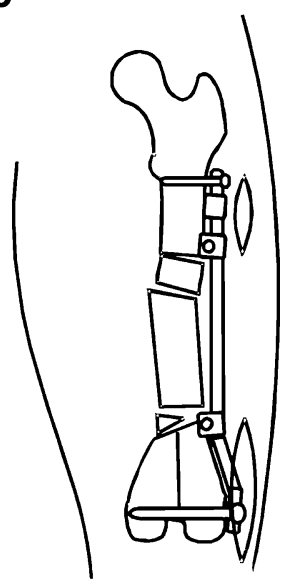

d

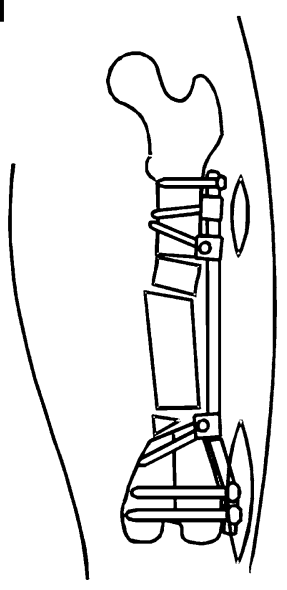

Fig. 4 Scheme of application of the SIF for condylar or condylar and diaphyseal fractures

Superficial infections were resolved by opening and cleaning the wound in two cases and with antibiotics in three cases. Three deep infections were treated by implant removal and external fixation, and one by implant removal and skeletal traction. Screw-breaking occurred 6-18 weeks in 19 fixations (2.6\%). In 15 cases, the anti-rotation screw was broken, whereas in three cases, the clamp screw was broken. In two cases $(0.3 \%)$, the bar was broken, both of which were at the connection to the trochanteric block. Post-operatively, there were misalignments with more than $5^{\circ}$ of angulation in the diaphyseal and metaphyseal area in two cases $\left(10^{\circ}\right.$ and $15^{\circ}$, respectively) and more than $8^{\circ}$ breakdown of collodiaphyseal angle in 14 cases. There was no malalignment of more than $5^{\circ}$ of rotation. Length discrepancy exceeding $15 \mathrm{~mm}$ happened in five cases $(0.8 \%)$. In four cases, the length discrepancy was $25 \mathrm{~mm}$ and in one it was $30 \mathrm{~mm}$, all after severe comminuted fractures. Cutout phenomenon occurred in 24 cases (3.7\% of trochanteric fractures). Spontaneous beyond-measurement sliding back of sliding screws from the femoral neck happened in 25 cases. In 15 cases, it was $20 \mathrm{~mm}$ and it did not affect fixation, while in ten cases, it was $40 \mathrm{~mm}$ or more and the screws were removed under local anesthesia (ordinarily, only one screw migrated). No deep venous thrombosis was observed. No fracture occurred through the screw holes. Patients did not complain of discomfort due to implant below the muscles. The results of three typical femoral fractures treated by the SIF are shown here: subtrochanteric fracture (Fig. 5), diaphyseal fracture (Fig. 6) and fracture of the distal femur (Fig. 7). Spontaneous axial dynamisation, $5 \mathrm{~mm}$ on average $(2-12 \mathrm{~mm})$, was observed in 71 $(23.8 \%)$ out of 738 fractures. The typical appearance of spontaneous dynamisation is shown in Fig. 8.
Radiologically, periosteal callus formation was distributed nearly equally around the fracture area (Fig. 5c).

For fractures of the upper femur, the Salvati and Wilson score showed excellent results in 356 fractures (54.7\%), good results in 203 fractures (31.2\%) and fair results in 92 $(14.1 \%)$. In diaphyseal and distal femur fractures, knee stiffness was observed in 27 fractures $(12.3 \%)$ : six after diaphyseal fracture showed up to $100^{\circ}$ knee flexion and 21 after distal femur fractures showed up to $110^{\circ}$ of flexion. In the rest of the patients, knee flexion was normal. Patients were examined by 5 out of 17 treating surgeons. Hardware removal was done in 139 patients: 49 after diaphyseal fixation, 91 after proximal femur fixation and 18 after distal femoral fixation.

\section{Discussion}

Fractures of the femur are a common problem in orthopaedic trauma. They can be regarded as fractures of different areas of the femur (proximal, diaphyseal, distal), but more and more fractures need to be regarded as complex fractures involving, for example, trochanteric and diaphyseal areas or condylar and diaphyseal or a combination of all of these areas. The most frequent fractures of the femur are fractures involving the proximal area. The most widely used implants for proximal femoral fracture treatments are intramedullary implants, such as gamma nail, proximal femoral nail (PFN) and intramedullary hip screw (IMHS) [13], while dynamic hip screw (DHS) has unexpectedly lost priority during the last several years, although this implant can preserve its position as a safe and effective solution [14]. For diaphyseal fractures, treatment with a 

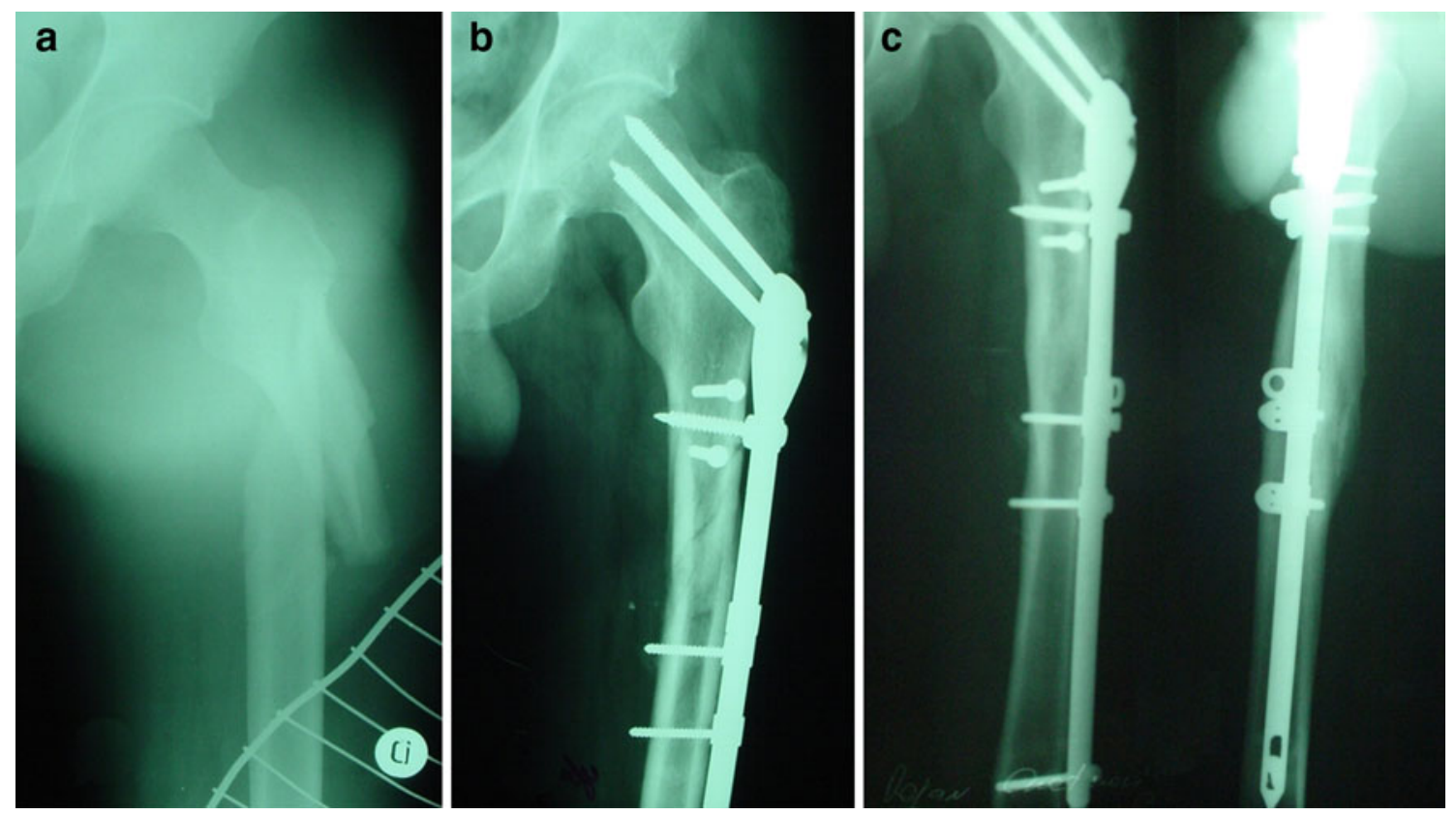

Fig. 5 Subtrochanteric femoral fracture (31-B3 type) fixed with the SIF. a X-ray after the injury; operation performed 3 days later. b X-ray 4 weeks after the operation. $\mathbf{c}$ X-ray 10 months after the operation

nail is the most frequently used technique. Typical complications in the osteosynthesis of inter- and sub-trochanteric femoral fractures with intramedullary nailing systems are as follows: post-operative fracture of the femoral shaft when a short nail is used, intra-operative femoral shaft fracture, problems in placing the distal locking screws, deep infections [15], "Z" phenomenon with implant hip penetration and "cut-out" phenomenon. DHS has frequent implant failure during the treatment of subtrochanteric fractures, followed by delayed union, but, also, "cut-out" phenomenon is not rare, as well as lateralisation of the proximal femur fragment. The final outcome of surgery for the fractures treated with DHS is good, with most patients returning to their pre-fracture level of accommodation and mobility [16]. Biomechanical cadaveric investigation used for comparing IMHS and the Medoff sliding plate (MSP) shows that, in a biaxially dynamised, three-part reverse oblique fracture, displacement of the proximal fragment can occur with the MSP [17]. The MSP gives increased dynamic capacity, which reduces the risk of complications [18]. Clinical study compared the results of standard Gamma nail (SGN) and the MSP, which has the possibility of dynamisation in two axes: axis of the femoral neck and the longitudinal femoral axis. If, intra-operatively, both axes of the MSP are adjusted to be active (biaxial dynamisation mode), then a lower rate of failure is obtained in trochanteric fractures treatment, in comparison to an unacceptably high rate of failure when MSP used in the biaxial dynamisation mode in subtrochanteric fractures [19]. A cadaveric study of the biomechanical properties of proximal femoral nailing (PFN) fixation showed it to be an effective fixation device [20]. The treatment of extracapsular hip fractures with PFN shows positive results in clinical studies [21]. The treatment of subtrochanteric fractures is challenging with this implant.

The SIF is successfully used for subtrochanteric fractures. It provides a short operative time, low blood loss, spontaneous biaxial dynamisation and healing in an optimal period of time without the need for secondary intervention [22]. Other implants like the DHS and the dynamic condylar screw (DCS) do not have axial dynamisation [23].

Regarding the diaphysis and metaphysis fractures, the use of plates can lead to non-union and/or implant failure [24]. For the treatment of diaphyseal femoral fractures, the gold standard today is intramedullary nailing [12, 25, 26]. Using current concepts of the intramedullary nailing of femoral shaft fractures yields high union rates and low complication rates when vigilance is maintained during preoperative planning, the surgical procedure and the postoperative period $[4,27]$. This method has two main advantages: it is minimally invasive and immediate weightbearing is normally allowed.

The effect of axial dynamisation is well recognised. The interlocking nailing of femoral fractures offers such a possibility $[28,29]$. For axial dynamisation of the interlocking nail, it is necessary to perform an additional operation. New plate designs minimise the disadvantages of plating with respect to cortical perfusion, although complications such as delayed union (up to 6.1\%) and implant failures (up to 7.4\%) still exist [30-33]. 


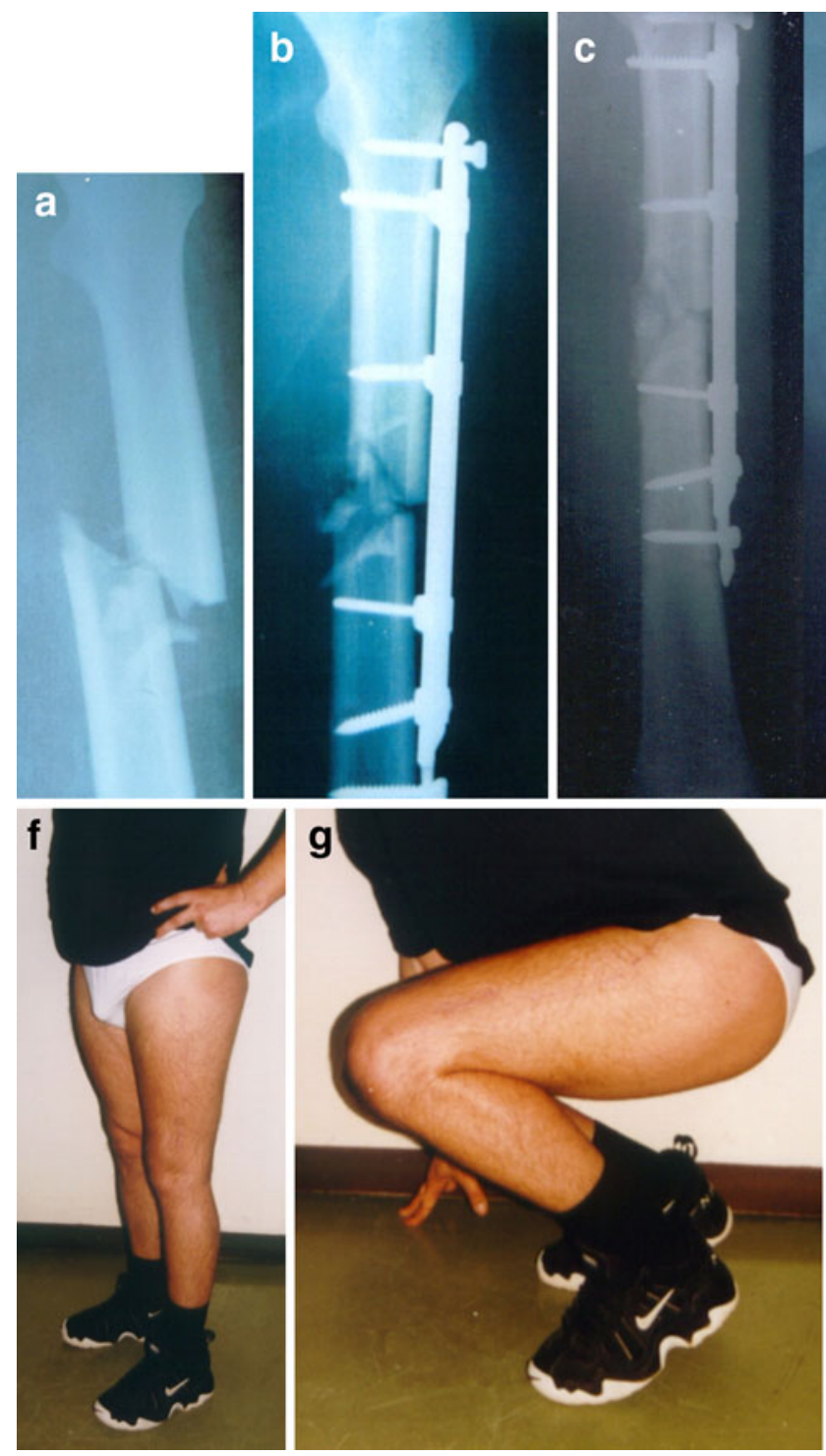

Fig. 6 Fracture of the femoral diaphysis (32-B2 type). a X-ray after the injury. b X-ray the day after fixation using the SIF. c X-ray 6 weeks after operation. d X-ray 6 months after operation. e X-ray after SIF removal (2 years after operation). f, g Functional result 4 months after the operation
Fig. 7 Two years after the fixation of a 33-C2 distal femoral fracture. a X-ray 2 years after the operation. b, c Functional result prior to SIF removal (2.5 years after the operation)
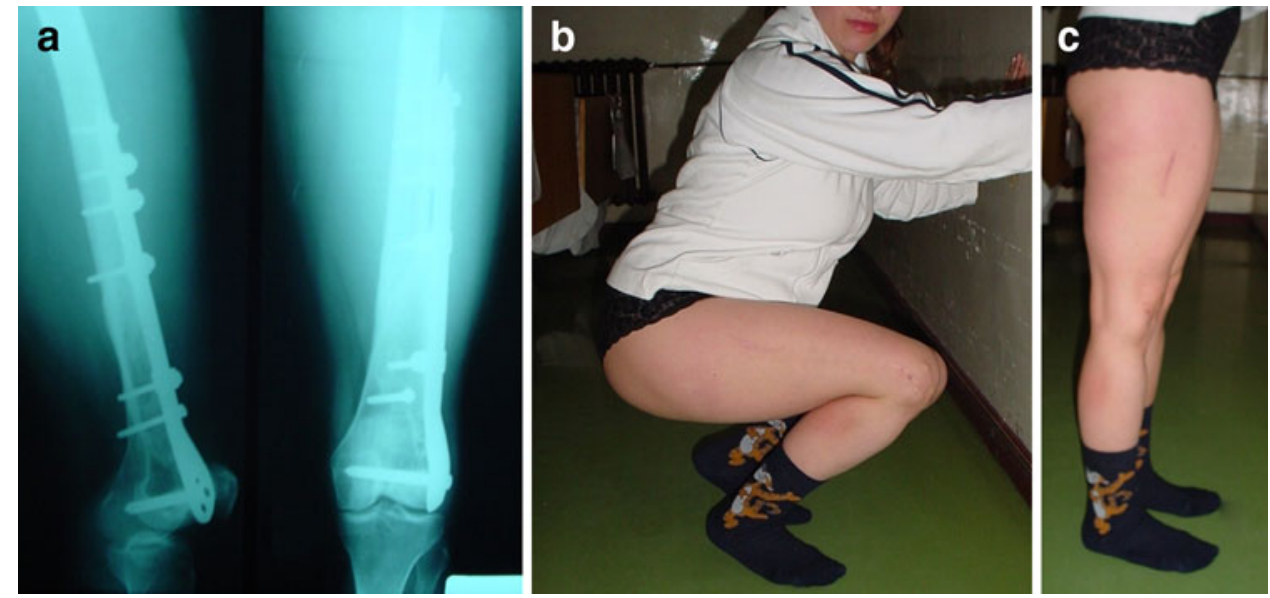


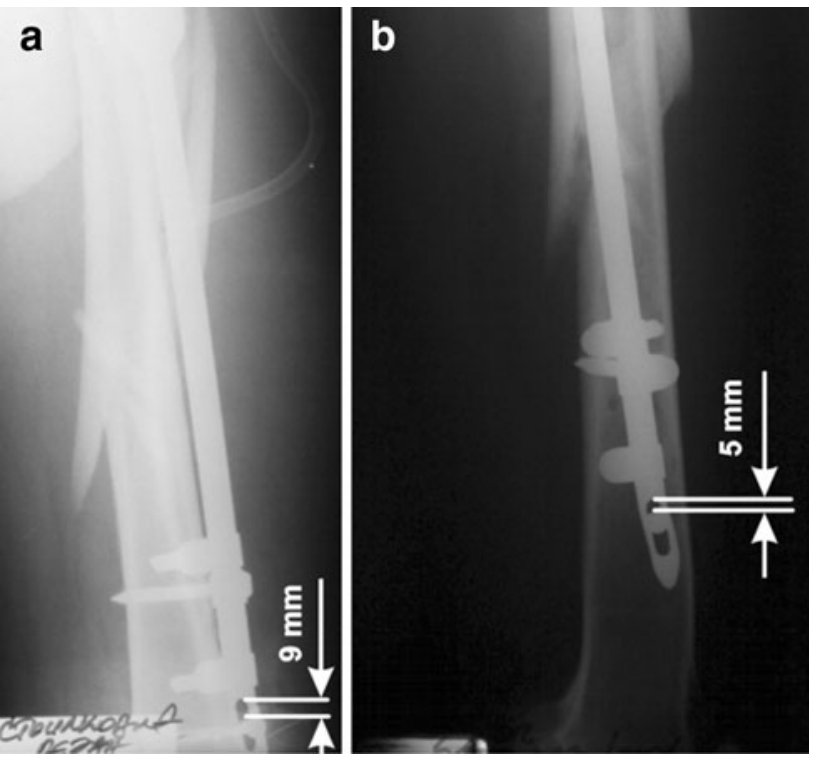

Fig. 8 Typical appearance of the spontaneous dynamisation of the SIF. a X-ray the day after the operation and $\mathbf{b} \mathrm{X}$-ray 12 weeks after the operation. Spontaneous axial dynamisation is visible, with $4 \mathrm{~mm}$ of biocompression-the head of the anti-rotating screw is more proximal in the dynamic unit slot and the distal clamp is more proximal in relation to the slot compared with immediately postoperative distances

Dynamisation is important for a minority of patients. In the literature available on PubMed, in one paper, we found that $11.6 \%$ of patients who underwent statically locked intramedullary fixation required dynamisation to achieve diaphyseal union [34]. In another series, union was obtained in all of the 19 patients who underwent locked intramedullary nailing, but in four $(21 \%)$ patients, healing occurred after dynamisation [35]. Dynamisation by removal of the locking screw opposite the fracture site accelerates the transformation and ossification of early fixation callus [36]. Some authors believe that dynamisation can accelerate fracture union, but cannot prevent non-union [37]. In our series, dynamisation happened spontaneously in $23.8 \%$ of patients. So, according to the literature data and our early experience with the SIF, it can be concluded that, in about $20 \%$ of femoral fractures, dynamisation is desirable. We do not know, in advance, which fractures (patients) will need dynamisation.

It is often recommended that the already used external fixation method for the femur should be transformed into one of the internal fixation methods $[38,39]$. We also perform transforming of the external fixation into internal using the SIF [40]. The SIF is a kind of extramedullary bar where interference with pin tracts can be avoided because the bar is narrow and can be introduced in different directions and because the components of the SIF (clamps) can slide and rotate onto the bar.
Using the bar and clamps, the dead space in the fracture area is excluded. From the biomechanical point of view, the SIF provides a balanced three-dimensional stability in the fracture area, which was confirmed by biomechanical investigations and experimental work conducted on 60 animals [41] but also clinically equally distributed periosteal callus formation around the fracture area, in the AP and LL views. The SIF provides three-dimensional stability with only one implant, as the screw can be introduced in up to $45^{\circ}$ of convergent orientation and this implant is also sufficiently elastic to stimulate the production of periosteal callus. The effect of spontaneous dynamisation has been proven radiologically. It turned out that the overall rate of delayed union and non-union decreased. Because of this spontaneous dynamisation feature, this internal fixator can be regarded as an intelligent implant. The spontaneous dynamisation effect is provided with the special construction of the clamps and screws. It is important for the surgeon to know that the selfdynamisation effect depends on the momentum of force used during the screwing and tightening of the clamps. At this moment, we do not know the accurate interdependence of the screwing force momentum and the activation of the dynamisation effect. The force momentum we use corresponds approximately to the force momentum that is used during the screwing into normal dynamic condylar plates. However, we carried out an analysis of our measurements, but these results are not presented here.

It has been shown that the SIF is a suitable internal device for the dynamic fixation of pertrochanteric fractures. It has the possibility of dynamisation in two axes (the femoral neck axis and the long femoral axis) and the operative technique is relatively simple, with minimal need for fluoroscopy [42].

During the use of the SIF, there were certain doubts that it could produce pressure on the muscles from beneath and cause discomfort to patients. Clinically, the patients did not have any complaints in this respect, except for three cases with mild or moderate complaints.

Biomechanical investigations show that axial stiffness, torsional rigidity and cyclical axial loading (fatigue test) are comparable with the locking compression plate (LCP) [24], but the results of these investigations are not presented here. We did not find an implant with a spontaneous dynamisation feature in the literature.

According to the first clinical results obtained after the use of the new SIF, it can be concluded that this implant provides good biological and biomechanical environments for femoral fracture healing. It is especially suitable for complex fracture treatments, such as comminuted fractures and segmental fractures involving the trochanteric or condylar area. Its application is relatively simple and this implant is suitable for a routine minimally invasive 
osteosynthesis. Further studies, however, are necessary in order to define the optimal force momentum of clamps and screws tightening and to evaluate the potential advantages or complications as compared to the existing intramedullary and plate fracture fixation.

Conflict of interest The author Milorad Mitkovic, has at this moment agreement with Traffix, producer of SIF, on temporary assignment to the use of patent.

Open Access This article is distributed under the terms of the Creative Commons Attribution Noncommercial License which permits any noncommercial use, distribution, and reproduction in any medium, provided the original author(s) and source are credited.

\section{References}

1. Weise K. 30 years of osteosynthesis: developments in surgical fracture treatment over the last three decades. Orthopade. 2010;39:122-31.

2. Perren SM, Z'Brun P. Bone loss after plating ("stress protection"). Injury Suppl. 1991;22:10-1.

3. Stockenhuber N, Schweighofer F, Bratschitsch G, Szyszkowitz R. UFN system. A method of minimal invasive surgical management of femoral shaft fractures. Langenbecks Arch Chir. 1996; 381:267-74.

4. Ricci WM, Gallagher B, Haidukewych GJ. Intramedullary nailing of femoral shaft fractures: current concepts. J Am Acad Orthop Surg. 2009;17:296-305.

5. Mitkovic MB, Bumbasirevic MZ, Lesic A, Golubovic Z. Dynamic external fixation of comminuted intra-articular fractures of the distal tibia (type $\mathrm{C}$ pilon fractures). Acta Orthop Belg. 2002;68:508-14.

6. Mitkovic M. New concept in external fixation. 1st ed. Nis, Serbia: Prosveta; 1993.

7. Mitkovic M. External fixation in traumatology-development and application of author's devices. 1st ed. Nis, Serbia: Prosveta; 1992.

8. Stojiljković P, Golubović Z, Mladenović D, Micić I, Karalejić S, Stojiljković D. External skeletal fixation of femoral shaft fractures in polytrauma patients. Med Pregl. 2008;61:497-502.

9. Mitković M, Bumbasirević M, Golubović Z, Mladenović D, Milenković S, Mićić I, Lesić A, Bumbasirević V, Pavlovic P, Karalejić S, Kuljanin G. New biological method of internal fixation of the femur. Acta Chir Iugosl. 2005;52:113-6.

10. Gustilo RB, Anderson JT. Prevention of infection in the treatment of one thousand and twenty-five open fractures of long bones: retrospective and prospective analyses. J Bone Joint Surg Am. 1976;58:453-8.

11. Müller ME, Allgöwer M, Schneider R, Willenegger H. Manual of internal fixation. 3rd ed. New York: Springer-Verlag; 1991.

12. Salvati EA, Wilson PD Jr. Long-term results of femoral-head replacement. J Bone Joint Surg Am. 1973;55:516-24.

13. Banan H, Al-Sabti A, Jimulia T, Hart AJ. The treatment of unstable, extracapsular hip fractures with the AO/ASIF proximal femoral nail (PFN) —our first 60 cases. Injury. 2002;33:401-5.

14. Verettas DA, Ifantidis P, Chatzipapas CN, Drosos GI, Xarchas KC, Chloropoulou P, Kazakos KI, Trypsianis G, Ververidis A. Systematic effects of surgical treatment of hip fractures: gliding screw-plating vs intramedullary nailing. Injury. 2010;41:279-84.
15. Suckel A, Helwig P, Schirmer A, Garbrecht M, Mocke U. Complication rate in the treatment of inter- and subtrochanteric femur fractures with two intramedullary osteosyntheses. Comparison of a conventional nailing system and a rotation stable fixation of the head-neck-fragment, gammanail and glidingnail. Zentralbl Chir. 2003;128:212-7.

16. Chirodian N, Arch B, Parker MJ. Sliding hip screw fixation of trochanteric hip fractures: outcome of 1,024 procedures. Injury. 2005;36:793-800.

17. Kummer FJ, Olsson O, Pearlman CA, Ceder L, Larsson S, Koval KJ. Intramedullary versus extramedullary fixation of subtrochanteric fractures. A biomechanical study. Acta Orthop Scand. 1998;69:580-4.

18. Lunsjö K, Ceder L, Stigsson L, Hauggaard A. Two-way compression along the shaft and the neck of the femur with the Medoff sliding plate: one-year follow-up of 108 intertrochanteric fractures. J Bone Joint Surg Br. 1996;78:387-90.

19. Miedel R, Ponzer S, Törnkvist H, Söderqvist A, Tidermark J. The standard Gamma nail or the medoff sliding plate for unstable trochanteric and subtrochanteric fractures. A randomised, controlled trial. J Bone Joint Surg Br. 2005;87:68-75.

20. Steinberg EL, Blumberg N, Dekel S. The fixion proximal femur nailing system: biomechanical properties of the nail and a cadaveric study. J Biomech. 2005;38:63-8.

21. Tyllianakis M, Panagopoulos A, Papadopoulos A, Papasimos S, Mousafiris K. Treatment of extracapsular hip fractures with the proximal femoral nail (PFN): long term results in 45 patients. Acta Orthop Belg. 2004;70:444-54.

22. Micic ID, Mitkovic MB, Park IH, Mladenovic DB, Stojiljkovic PM, Golubovic ZB, Jeon IH. Treatment of subtrochanteric femoral fractures using Selfdynamisable internal fixator. Clin Orthop Surg. 2010;2:227-31.

23. Kulkarni SS, Moran CG. Results of dynamic condylar screw for subtrochanteric fractures. Injury. 2003;34:117-22.

24. Stoffel K, Dieter U, Stachowiak G, Gächter A, Kuster MS. Biomechanical testing of the LCP-how can stability in locked internal fixators be controlled? Injury. 2003;34(Suppl 2):B11-9.

25. Bishop JA, Rodriguez EK. Closed intramedullary nailing of the femur in the lateral decubitus position. J Trauma. 2010;68:231-5.

26. Montanini R, Filardi V. In vitro biomechanical evaluation of antegrade femoral nailing at early and late postoperative stages. Med Eng Phys. 2010;32:889-97.

27. Selvakumar K, Saw KY, Fathima M. Comparison study between reamed and unreamed nailing of closed femoral fractures. Med $\mathrm{J}$ Malaysia. 2001;56(Suppl):D24-8.

28. Basumallick MN, Bandopadhyay A. Effect of dynamization in open interlocking nailing of femoral fractures. A prospective randomized comparative study of 50 cases with a 2-year followup. Acta Orthop Belg. 2002;68:42-8.

29. Mukhopadhyay AS, Mukherjee J, Sengupta A. The role of dynamisation vis-à-vis non-dynamisation after closed interlocking nailing in cases of closed tibial shaft fractures in adults. J Indian Med Assoc. 2010;108:361-2, 364.

30. Schütz M, Müller M, Kääb M, Haas N. Less invasive stabilization system (LISS) in the treatment of distal femoral fractures. Acta Chir Orthop Traumatol Cech. 2003;70:74-82.

31. Schütz M, Südkamp NP. Revolution in plate osteosynthesis: new internal fixator systems. J Orthop Sci. 2003;8:252-8.

32. Perren SM. Evolution of the internal fixation of long bone fractures. The scientific basis of biological internal fixation: choosing a new balance between stability and biology. J Bone Joint Surg Br. 2002;84:1093-110.

33. Davison BL. Varus collapse of comminuted distal femur fractures after open reduction and internal fixation with a lateral condylar buttress plate. Am J Orthop (Belle Mead NJ). 2003;32:27-30. 
34. Lepore L, Lepore S, Maffulli N. Intramedullary nailing of the femur with an inflatable self-locking nail: comparison with locked nailing. J Orthop Sci. 2003;8:796-801.

35. Ertürer E, Tekkeşin M, Dirik Y, Aksoy B, Oztürk I. Radiographic and functional results of osteosynthesis with locked intramedulary nailing of subtrochanteric fractures of the femur. Acta Orthop Traumatol Turc. 2004;38:265-9.

36. Brug E, Pennig D. Indications for interlocking nailing. Unfallchirurg. 1990;93:492-8.

37. Wu CC. The effect of dynamization on slowing the healing of femur shaft fractures after interlocking nailing. J Trauma. 1997;43:263-7.

38. Nowotarski PJ, Turen CH, Brumback RJ, Scarboro JM. Conversion of external fixation to intramedullary nailing for fractures of the shaft of the femur in multiply injured patients. J Bone Joint Surg Am. 2000;82:781-8.
39. Höntzsch D, Weller S, Engels C, Kaiserauer S. Change in the procedure from external fixator to intramedullary nailing osteosynthesis of the femur and tibia. Aktuelle Traumatol. 1993; 23(Suppl 1):21-35.

40. Stojiljković PM, Golubović ZS, Mitković MB, Mladenović DS, Micić ID, Stojiljković DM, Karaleić SS, Najman S. Treatment of femoral shaft fractures in polytrauma patients using Mitkovic type internal fixator. Acta Chir Iugosl. 2007;54(2):33-8.

41. Gajdobranski DJ. Influence of different methods of internal fixation on bone callus characteristics in experimental animals. Doctoral dissertation, Medical Faculty, University of Nis, Serbia, 2004.

42. Mitković MB, Bumbasirević M, Milenković S, Micić ID, Mitković MM, Mitković MM, Mladenović DS, Todorovi MD. Fractures of the upper part of the femur treated with Mitkovic selfdynamisable internal fixator (SIF). Acta Chir Iugosl. 2010;57:103-7. 